\title{
Shock intensity and conditioned defensive burying in rats
}

\author{
DALLAS TREIT, JOHN P. J. PINEL, and LORI J. TERLECKI \\ University of British Columbia, Vancouver, British Columbia V6T IW5, Canada
}

Rats shocked once by a stationary wire-wrapped prod affixed to the side of the test chamber buried the prod with bedding material from the floor of the chamber. Although this conditioned defensive burying response occurred reliably at a wide range of shock intensities, subjects receiving more intense shock spent more time burying the prod. This positive relation between the amount of conditioned burying and the severity of the aversive stimulus is consistent with the view that burying is a defensive response.

In most studies of avoidance learning, animals are trained to reduce the probability of an aversive stimulus by fleeing from its source (active avoidance), by staying away from its source (passive avoidance), or by blocking its administration (e.g., leverpress avoidance). Pinel and Treit (1978) have recently reported that rats will approach a source of aversive stimulation and bury it, provided that the rat has access to burying materials and the aversive stimulus is well-defined. Avoidance behavior that is directed toward sources of aversive stimulation presents special problems for most existing theories of aversive conditioning. Burying behavior brings into question the intuitive assumption that an aversive stimulus reduces the probability of a response that it follows (e.g., Fantino, 1973) or is a stimulus from which the animal inevitably withdraws (Glickman \& Schiff, 1967). This kind of assumption, which is fundamental to most theories of avoidance learning, was clearly violated by the results of Pinel and Treit (1978). For example, in one study, every rat shocked by one of two identical shock sources (wire-wrapped wooden dowels) mounted at opposite ends of the chamber selectively approached and buried the shock source with bedding from the floor of the chamber. It thus appears that in situations in which the source of aversive stimulation is readily identifiable, rats reliably "avoid" by approaching and coping with the stimulus.

One possible interpretation of the rat's failure to flee from the source of shock is that the shock was not in fact aversive; however, the procedures used by Pinel and Treit (1978) make this interpretation unlikely. The shocks, although brief (duration determined by the latency of each subject's withdrawal reflex; mean = $42.9 \mathrm{msec}, \mathrm{SD}=9.8$ ), were very intense (mean $=7.9 \mathrm{~mA}$, $\mathrm{SD}=1.5$ ) compared with the electric shocks used in

This research was supported by a grant from the National Research Council of Canada awarded to J. P. J. Pinel. Reprints may be obtained from John Pinel, Department of Psychology, University of British Columbia, Vancouver, British Columbia V6T 1W5, Canada. most studies of avoidance learning. Although the use of such intense shock made it difficult to argue that the shock level was too low to be aversive, it did raise the possibility that the rats' burying behavior might actually be a curious artifact of the severe shock and therefore of no major relevance to general theories of aversive conditioning. Thus, one purpose of the following experiment was to show that rats will approach and bury a source of electric shock despite substantial variations in shock intensity. A second objective was to describe the relation between shock intensity and conditioned defensive burying.

\section{METHOD}

The subjects were 60 naive male hooded rats (Canadian Breeding Farm and Laboratories, St. Constant, Quebec) weighing $250-500 \mathrm{~g}$ at the time of testing. Each rat was individually housed in a $24 \times 18 \times 18 \mathrm{~cm}$ wire-mesh cage under controlled illumination (12-h light/dark cycle), with continuous access to Purina Laboratory Chow and water.

All rats were handled and exposed, in groups of four or five, to the $44 \times 30 \times 44 \mathrm{~cm}$ Plexiglas test chamber for 30 -min periods on each of 4 consecutive days. During all phases of the experiment, the chamber floor was covered evenly with $5 \mathrm{~cm}$ of regular grade San-i-cel, a commercial bedding material (Paxton Processing Company, Paxton, Illinois). On Day 5, the rats were randomly assigned to one of five conditions $(n=12)$. The animals in the four experimental conditions were placed individually in the center of the chamber, facing away from a wooden prod $(6.5 \mathrm{x}$ $.5 \times .5 \mathrm{~cm}$ ) that had been fixed to the center of the wall at one end of the test chamber, $2 \mathrm{~cm}$ above the level of the bedding material. When the rats in these groups first touched the prod with a forepaw, a brief shock, initiated by the experimenter and terminated by the withdrawal of the subject, was delivered between two uninsulated wires wrapped tightly around the prod. Rats in the four experimental groups were shocked at $.5,3.5$, 6.5 , or $10 \mathrm{~mA}$; rats in the control group $(n=12)$ were treated in the same manner but were not shocked. Shock intensities were manipulated by adjusting the resistance in series with the subject and the $800-\mathrm{V}$ current source. The actual intensity and duration of the current flow was recorded on an oscilloscope in each case. Following contact with the prod, each subject was removed from the test chamber for $1 \mathrm{~min}$ before being returned to the chamber for a 15-min observation period. During this test period, the behavior of each subject was viewed by closed-circuit television, and the duration of burying (i.e., the time spent moving or 
spraying the bedding material toward or over the prod) was recorded on an event recorder (see Pinel \& Treit, 1978, for a detailed description of the burying response). In addition, each rat's latency to enter a $7-\mathrm{cm}$-square area around the prod was recorded. After each test, the height of the bedding material at the prod was measured.

\section{RESULTS}

Figure 1 shows that experimental rats buried the localized source of shock at a variety of shock intensities. A priori comparisons between each experimental group mean and the control group mean confirmed that shocked subjects spent significantly more time burying the prod at each shock intensity except $.5 \mathrm{~mA}[.5 \mathrm{~mA}$ : $\mathrm{t}(22)=1.36, \mathrm{p}>.10 ; 3.5 \mathrm{~mA}: \mathrm{t}(22)=3.91, \mathrm{p}<.0007$; $6.5 \mathrm{~mA}: \mathrm{t}(22)=4.23, \mathrm{p}<.0003 ; 10 \mathrm{~mA}: \mathrm{t}(22)=5.29$, $\mathrm{p}<.00002]$. Because the a priori comparisons in this study were nonorthogonal (Winer, 1962), a percomparison alpha level of .0125 was employed, making the overall alpha level for the experiment .05 .

A similar analysis of the height of the bedding accumulated at the prod by the rats in each of the five groups corroborated the behavioral results. The shocked animals in all but the $.5-\mathrm{mA}$ group accumulated significantly higher piles of bedding at the prod than did the unshocked control subjects $[.5 \mathrm{~mA}: \mathrm{t}(22)=1.18, \mathrm{p}>.10$; $3.5 \mathrm{~mA}: \mathrm{t}(22)=2.96, \mathrm{p}<.01 ; 6.5 \mathrm{~mA}: \mathrm{t}(22)=3.14$, $\mathrm{p}<.004 ; 10 \mathrm{~mA}: \mathrm{t}(22)=3.50, \mathrm{p}<.002$ ]

Because the amount of shock actually received by each experimental subject was influenced by its resistance, the intensity of shock for a particular animal differed somewhat from the intended level. Rats in the .5-, 3.5-, 6.5-, and 10-mA groups received average peak

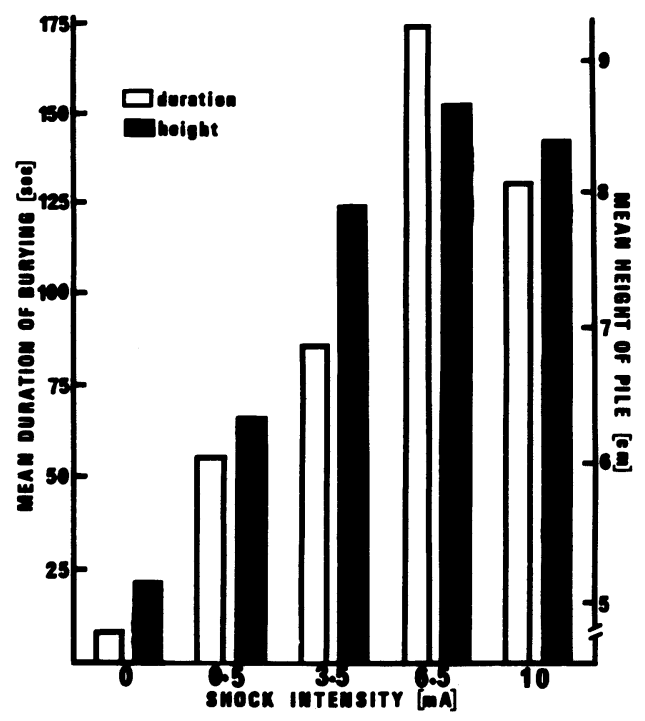

Figure 1. Mean duration of burying and the height of the bedding accumulated by rats shocked at different intensities. The initial height of the bedding was $5 \mathrm{~cm}$. intensities of $.4(\mathrm{SD}=.11), 3.2(\mathrm{SD}=1.4), 6.4(\mathrm{SD}=$ $1.2)$, and $9.7(\mathrm{SD}=3.1) \mathrm{mA}$, respectively. These data provided the opportunity to examine the relationship between shock intensity and conditioned defensive burying behavior. The product-moment correlation between the peak shock intensity received by each experimental rat and the duration of its burying behavior $(r=.285)$ was statistically significant $(p<.05)$. Thus, conditioned defensive burying was more prevalent in subjects that received shock of high intensity. In addition, those rats that returned to the prod quickly after their initial reflexive withdrawal from the shock spent more time burying. The correlation between each experimental animal's latency to enter the 7-cm-square area around the prod and the amount of time spent burying was $-.380(p<.02)$.

\section{DISCUSSION}

The results of the present experiment established that conditioned defensive burying occurs at a variety of shock intensities; burying behavior occurred reliably at all shock intensities above $.5 \mathrm{~mA}$. Thus, it is clear that conditioned defensive burying is not specific to the particular intensity of shock used in all previous studies of this phenomenon.

The negative correlation observed between the latency to approach the prod and the duration of burying is particularly interesting in view of the fact that latency has been the accepted measure of retention in comparable situations (one-trial passive avoidance; cf. Pinel, 1968). It is assumed that subjects approaching a shock source do not remember the previous consequences of such behavior. The observation that those rats returning to the prod sooner engaged in more defensive burying constitutes a direct challenge to this pervasive assumption.

Pinel and Treit (1978) provided two lines of evidence that conditioned burying serves a defensive function: (1) Rats inevitably buried sources of aversive stimulation rather than available alternatives, and (2) the burying response potentially afforded the rats some protection from future aversive stimulation. The positive correlation between the intensity of the aversive stimulus and the amount of conditioned burying observed in the present study supports the view that conditioned burying is appropriately viewed as a defensive response; as the intensity of the shock increased, the subjects spent more time burying.

McKim and Lett (1979) recently questioned the view that burying is a defensive response because their review of the literature yielded no accounts of burying in response to threat in the rat's natural environment. In this regard, Calhoun (1962) claimed that wild rats of low status buried the entrance to their burrows to impede the entry of aggressive conspecifics, and Hudson (1950) wrote that ground squirrels commonly protect themselves from traps or reptile predators by burying them. Although the empirical basis for the statements of Calhoun and Hudson is unclear, more systematic investigations of defensive burying in rodents confirmed some of their conclusions. Owings, Borchert, and Virginia (1977) reported that California ground squirrels induced defensive behavior or flight in approaching snakes by spraying sand at them. They kicked sand at the snakes with forward thrusting movements of the forepaws apparently identical to those used by the rats in the present experiments to move the bedding material. Because this behavior was also observed in laboratory-reared ground squirrels the first time that they encountered a snake, but not a mechanical control object (Owings \& Coss, 1978), it appears that the tendency of ground squirrels to spray sand at snakes is unconditioned. 
Supporting these reports of defensive burying by wild rodents are two recent studies of defensive burying in laboratory rats exposed to sources of aversive stimulation other than shock (Terlecki, Pinel, \& Treit, 1979; Wilkie, MacLennan, \& Pinel, 1979). In the study by Wilke et al., every rat exposed to a toxicosis-inducing injection of lithium following consumption of a novel saccharin solution buried the spout from which the saccharin was consumed. Terlecki et al. reported that when rats first encountered a mousetrap or a flashbulb in a chamber to which they had been habituated, they buried it with bedding material from the floor of the chamber, whereas rats previously habituated to the trap or the flashbulb did not. Conversely, rats did not bury a prod or a length of polyethylene tubing, even on first encounter. However, almost every rat struck by the trap, shocked by the prod, exposed to an air blast from the tube, or exposed to a flash of the bulb buried the respective source of aversive stimulation with the bedding material, even when a comparable control object was present during conditioning and testing. Rats seem to enter the experimental environment with an already established tendency to bury some objects (unconditioned defensive burying) but not others, and they readily learn to selectively bury an object that has been the source of any one of a variety of aversive stimuli (conditioned defensive burying).

\section{REFERENCES}

Calmoun, J. B. The ecology and sociology of the Norway rat. Bethesda, Md: U.S. Department of Health, Education, and Welfare, 1962.

Fantino, E. Aversive control. In J. A. Nevin \& G. S. Reynolds
(Eds.), The study of behavior. Glenview, Ill: Scott, Foresman, 1973.

Glickman, S. E., \& Schiff, B. B. A biological theory of reinforcement. Psychological Review, 1967, 74, 81-109.

Hudson, B. B. One trial learning in the domestic rat. Genetic Psychology Monographs, 1950, 41, 99-145.

McKıм, W. A., \& Letт, B. T. Spontaneous and shock-induced burying in two strains of rats. Behavioral and Neural Biology, 1979, 26, 76-80.

Owings, D. H., Borchert, M., \& Virginia, R. The behaviour of California ground squirrels. Animal Behaviour, 1977, 25, 221-270.

Owings, D. H., \& Coss, R. G. Snake mobbing by California ground squirrels: Adaptive variation and ontogeny. Behavior, 1978, 62, 50-69.

Pinel, J. P. J. Evaluation of the one-trial passive avoidance task as a tool for studying ECS-produced amnesia. Psychonomic Science, 1968, 13, 131-132.

Pinel, J. P. J., \& Treit, D. Burying as a defensive response in rats. Journal of Comparative and Physiological Psychology, 1978, 92, 708-712.

Terlecki, L. J., Pinel, J. P. J., \& Treit, D. Conditioned and unconditioned defensive burying in the rat. Learning and Motivation, 1979, 10, 337-350.

Wilkie, D. M., Maclennan, A. J., \& Pinel, J. P. J. Rat defensive behavior: Burying noxious food. Journal of the Experimental Analysis of Behavior, 1979, 31, 299-306.

Winer, B. J. Statistical principles in experimental design. New York: McGraw-Hill, 1962.

(Received for publication April 15, 1980.) 